\title{
Genetic information and life insurance: a 'real' risk?
}

\author{
Yann Joly*, Bartha M Knoppers and Béatrice Godard \\ Centre de recherche en droit public, Faculty of Law, University of Montreal, Montreal, Canada
}

Public concern about genetic discrimination, particularly access to insurance following genetic testing, has been reported in the literature. This paper aims to separate myths from realities regarding genetic discrimination in life insurance and to underline the positive aspects of allowing insurers access to relevant genetic information for underwriting purposes. We present a review of the literature pertinent to discrimination in life insurance and a comparative analysis of industries guidelines. There are few reported cases in the literature of validated genetic discrimination. However, the benefits to be gained by allowing insurers access to relevant genetic data could justify fostering a more active role in the use of genetic information by insurance companies.

European Journal of Human Genetics (2003) 11, 561-564. doi:10.1038/sj.ejhg.5200998

Keywords: genetic testing; life insurance; discrimination; insurers; genetic data

In the early 1980s, advances in the fields of molecular genetic and genetic epidemiology led to the development of the first genetic tests for disease predisposition. Public interest in such testing grew, yet fear of the discriminatory use of test results by insurers led to alarmist predictions such as the creation of a new genetic underclass for whom insurance would be unaffordable. ${ }^{1}$ This dark vision of genetic discrimination might be more myth than reality. It remains to be seen whether in industrialized countries with universal health-care systems, access to at least a minimum of life insurance (eg to obtain a mortgage, a loan, or to buy a car...) will continue to be seen as a privilege as opposed to a socioeconomic right.

We aim to demonstrate that in the case of predictive genetic testing, it may actually be in the interest of the applicant to let the insurer determine what constitutes relevant information for life insurance underwriting. To present this position, we will begin by analysing the notion of genetic discrimination as it applies to the life insurance contract. Then, we will explore the different solutions advanced by government and industry. Finally, we will discuss the positive aspects of allowing life insurers

*Correspondence: Y Joly, Pavillon Maximilien-Caron, 3101, Chemin de la Tour, Montréal, QC, Canada H3T 1J7. Tel.: +514 3436111 (5020); fax: +514 343 2122; E-mail: yann.joly@umontreal.ca Received 24 September 2002; revised 29 January 2003; accepted 10 February 2003 access to predictive genetic test results. Considering current public unease, we recommend, however, that the insurance industry adopt a temporary, voluntary moratorium along with publicized code of conduct explaining its practices.

\section{Genetic discrimination}

The notion of genetic discrimination as it relates to life insurance is of central importance to the debate: Indeed,

[I]n the insurance contract, rational, scientifically sound and empirically supported discrimination is possible. Discrimination among risks is considered ethically problematic only where there is no sound actuarial basis for the manner in which the risks are classified, or individuals of the same risk class are treated differently. Hence, the more information available to the insurers the better, the more precise the discrimination, the greater the actuarial fairness of the system. ${ }^{2}$

Taking this into consideration, it is easy to understand why recent literature has reported few cases of validated genetic discrimination in the life insurance industry. ${ }^{3}$ The price of genetic testing ${ }^{4}$ and the fact that actually, very few genetic tests are deemed relevant for underwriting 
by actuaries ${ }^{5}$ might also explain these findings. Furthermore, in countries with a universal health-care system, we would posit that the Constitutions and the human rights legislation of most countries offer the necessary protection for life insurance applicants. ${ }^{6}$

To understand 'actuarially rational' discrimination, ${ }^{7}$ one has to realize that the use of genetic information for life insurance underwriting purposes is not new: insurers have been requesting information about an applicant's family history for decades. Determining the degree of risks depends on an assessment based on scientific knowledge. ${ }^{8}$ Indeed, the use of genetic test results for underwriting allows applicants to benefit from a negative result to lower a high premium based on a family history of disease. In the case of a positive test result, applicants might have to face a small increase or no increase at all in their premium, their genetic risk having already been accounted for by the family history questionnaire. ${ }^{7}$

Public fears have to be taken seriously however. They originate from both a lack of knowledge and a misunderstanding of both the implications of genetic testing and of the mutuality aspect of the insurance contract itself. ${ }^{4}$ The insurance contract implies a pooling of similar risk in return for a proportional contribution by each individual member of the group. It is the applicant themselves grouped together that contribute to the indemnification of the victim. The insurer serves as an intermediary responsible for the pooling of the information and of the premiums. We would posit that public fears could be diminished by a greater transparency of the system and an harmonization of the norms governing genetic and insurance. People need to be reassured about the life insurance implications of genetic testing as a diagnostic tool or before participating in research studies.

\section{Existing solutions}

Public pressure has forced both government and industry to react. Several avenues were raised for solving the genetics and insurance dilemma. Three major approaches have emerged in the last decade: legislative prohibition (i), moratoria (ii) and the status quo (iii). ${ }^{6}$

\section{Legislative prohibition}

The most radical of these approaches is a legislative prohibition. It consists of either forbidding insurers from inquiring about the genetic condition of an applicant or, in prohibiting genetic testing at large. (See for example Israel, Genetic Information Law, 5761-2000). This approach seems to create more problems than it solves. 'Major definitional problems arise from the confusion surrounding the question of what actually constitutes genetic information, and what in fact, is a genetic test'. Cholesterol tests are a case in point. ${ }^{7}$ Also, one has to understand that while it may be possible to restrict the practice of molecular genetic testing, there are other less technical means of obtaining genetic information. The legitimized use of family history is an obvious example. ${ }^{9}$ Another problem with this prohibitive approach is that individuals with a family history reflecting the existence of a genetic condition will not be able to benefit from a negative test result.

Furthermore, according to Anderlik and Rothstein: ${ }^{2}$

(S)eparate treatment of genetic information increases the stigma attached to genetic conditions. People may believe that because genetic conditions are singled out for protection, they must be particularly shameful. Separate treatment may also foster genetic reductionism-the attribution of all traits, health problems, and behaviours to genes without regard to other factors-and genetic determinism-the belief that an individual's future is defined and predicted by genetic make up and cannot be changed.

A less radical version of this approach has been used in the Netherlands. It consists of a prohibition on insurers to ask the applicant for past genetic test results for an insurance contract that is under a predetermined amount. This allows individuals to obtain a basic amount of life insurance. Although this variant of the legislative approach has some appeal, the same result can be obtained through the moratoria approach, while avoiding the negative 'genetic exceptionalism' mentioned above.

\section{Moratoria}

The use of moratoria, albeit temporary in application, offers an appealing middle road. Here, the limitation on the use of genetic information for life insurance purposes comes from the initiative of the insurers themselves (although sometimes with the support of the government). The strength of moratoria varies greatly from one country to another. In some countries, insurers will limit themselves from requiring genetic testing of the applicants, while in others the results of previously taken genetic tests will not be demanded. Some moratoria have a 'ceiling' over which the protection no longer applies. Others only protect genetic information derived from research and would have access to clinical test results.

Yet this temporary solution, allows the industry to evaluate the statistical value of genetic testing for underwriting before taking a final decision. 'From the perspective of public relations, it enables the insurance industry to appear sensitive to public concerns and responsive to criticism'. ${ }^{8}$ The major drawback of a moratorium is the difficulty for enforcement by the industry on recalcitrant members. 


\section{Status Quo}

Under the status quo approach, the decision is neither legislation nor moratoria and thus, the insurance industry can decide what would constitute relevant genetic information for life insurance underwriting. This approach assumes that competitive market forces will prevent undue discrimination and that insurers are currently not using or asking for genetic tests results. Although this approach may be the most adequate, the fact that it does not take public anxiety into consideration greatly diminishes its appeal. ${ }^{6}$

\section{Positive aspects of access by life insurers}

Considering that a legislative prohibition forbidding insurers to access genetic tests results might not be the best solution, a question then comes to mind: what benefits could be gained from letting insurers access genetic test results? We will answer this question by first presenting the perspective of the insurer, then we will analyse current guidelines proposed by the life insurance industry to find what might be the advantage for the consumer.

Actuaries would rightfully argue that according to the principle of mutuality underlying the insurance contract, it is the clients themselves who by joining together contribute to their possible, future compensation. The insurer is only an intermediary in charge of spreading the risk and handling the common contributions of information. Thus, it is in the interest of all parties that the insurance contract be concluded with the utmost good faith. Accordingly, the applicant should communicate to the insurer all relevant information necessary for a proper assessment of the risk. Not only should all questions be answered truthfully, but even when no questions are asked, all relevant facts should be divulged.

The insurance contract laws of most countries, in fact, require this type of full disclosure. If a 'genetic exception', was made following a positive genetic test result, individuals may try to buy large policies at a favourable premium based on genetic information that is not shared with the insurer and so create an asymmetry of information. Should this practice become widespread, 'then the whole of mutuality-based insurance could collapse. ${ }^{7}$ Even though recent surveys have demonstrated this fear of the insurers to be mostly unfounded, ${ }^{10,11}$ the potential for adverse selection certainly exists if insurers are barred from accessing all information relevant to the contract.

Apart from eliminating the risk of adverse selection, giving insurers access to genetic test results can have a variety of positive effect for the consumers. Such practice will stimulate actuarial research, result in more data, and so a general improvement in fair actuarial risk assessment. The insurance industry being both competitive and profitdriven, it is in the insurers best interests to insure a maximum number of customers. Thus research by the industry could focus on using genetic tests to broaden the insurability of the general population and not the opposite. For example, research by American actuaries ${ }^{12}$ has demonstrated that in the case of ovarian or breast cancer, the possibility of adverse selection was very low in the case of term life insurance. Insurers did not need to access genetic test results if they applied strict underwriting rules consisting of requesting cancer history and onset age for all relatives.

An illustration of the determination of life insurers to cover a maximum number of applicants can be found in the Irish Insurance Federation Code of Genetic Testing: 'In a case where the underwriter concludes that the risk is too great to insure, alternative terms should be offered where possible $[. . .]^{\prime}$. $^{13}$

Several insurance associations have recognized that an early genetic diagnosis allows the applicant the opportunity to make better-informed choices, that is, changes in lifestyle and preventive intervention potentially leading to a better prognosis. Indeed, the Investment and Financial Services Association Limited (IFSA), representing the Australian life insurance industry stipulates in its Genetic Testing Policy that: '[W]hen assessing the overall risk associated with a particular genotype, [...] insurers will take into account the benefits of special medical surveillance, early medical intervention and the likelihood of successful treatment. ${ }^{14}$ In Canada, the Canadian Institute of Actuaries recommends that a negative test result be taken into account in the establishment of the premium. ${ }^{15}$

The promise of genetic testing has motivated insurers to improve their knowledge of genetics. On this issue the American Academy of Actuary in Genetic Information and Voluntary Life Insurance (1998) states: 'The Academy believes that further research should be undertaken on the insurance-related problems raised by genetic testing. Such research should be directed toward identifying and building support for solutions that will both provide increased options for individuals with genetic disadvantages and maintain a sound life insurance system.' Leading some associations to hire expert geneticists to act as consultants. $^{6}$ The IFSA has adopted a policy that 'all underwriting decisions involving a genetic test, whether or not the test was a significant factor in the decision, should be thoroughly documented, so that adequate information can be provided to the applicant on request. ${ }^{10}$ This approach ensures a degree of transparency and informs the applicant of the implications of any genetic information. Such transparency is needed if the industry means to reassure and inform the population.

One of the most interesting efforts undertaken by life insurers is the example of the United Kingdom. In response to the pressure from both public and government, the Association of British Insurers (ABI) has adopted a reflexive system. Such a reflexive system invokes a mixture of moratorium, codes of conduct and regulation through state oversight. This oversight gives a greater credibility to the moratorium and ensures that public opinion will be heard via their elected representatives. ${ }^{9}$ 


\section{Conclusion}

From this short analysis, it appears unlikely that people would be completely barred from obtaining life insurance because of a genetic test result. Applicants may have to face an increase in their premium in relation to their excess mortality risk, or no increase at all if their genetic risk has already been accounted for via a family history questionnaire. In rare cases, such an increase could prohibit some people from getting life insurance at all.

Ultimately, the nature of the life insurance contract demands that insurers be given access to all genetic information relevant for underwriting. Historically, life insurers have always been able to request all relevant health information prior to concluding a life insurance contract. It is given that the highly personal and familial nature of genetic information differentiates it from other types of medical information, ${ }^{16}$ but that difference alone does not justify a treatment that could have a detrimental effect on the insurance industry as a whole. 'The assumption that all things genetic involve especially serious or unique ethical risk and therefore require novel ethical principle and/or special regulatory responses ${ }^{\prime 17}$ ultimately, leads to genetic exceptionalism.

A solution that may be satisfactory to life insurers while still taking into account public opinion, would be for the industry, while gathering more evidence on the relation between genetic tests and mortality rates, to make use of the moratorium system and publish a code of conduct (in concert with the population) explaining the different categories it uses. This will ensure the transparency of the system. While not a perfect solution, it is one that will protect insurers and applicants while the industry gathers all necessary data to refine actuarial calculation. During such a transition period, the general population will benefit from a limited protection and people will be able to better inform themselves on the implications of their genetic risk. The ability of the life industry to enforce moratoria being yet undetermined, governmental oversight would ensure the dependability of the system along with popular acceptance.

\section{Acknowledgements}

The authors recognize the financial support from the Canadian Institute of Health Research for the project InHeRiT BRCAs.

\section{References}

1 Lemmens T: Selective justice genetic discrimination and insurance: should we single out genes in our laws? McGill LJ 2000; 45: 347-412.

2 Anderlik MR, Rothstein MA: Privacy and confidentiality of genetic information: what rules for the new science. Ann Rev Genom Hum Genet 2001; 2: 401-433.

3 Wertz DC: 'Genetic discrimination:' results of a survey of genetics professionals, primary care physicians, patients and public. Health Law Review 1999; 7: 7-8.

4 Dicke AA: Genetic risk and voluntary insurance. Contingencies 1996; 52-56.

5 Munich Re Group. Genetic testing and insurance - a global view, 2000. Online: <http://www.munichre.com > (date accessed: May 5 2002), p 24.

6 Knoppers BM, Godard B, Joly Y: Life insurance and genetics: a comparative international overview; in Rothstein M (ed): Life insurance: medical underwriting and social policy (in press).

7 Rothstein MA, Anderlik MR: What is genetic discrimination, and when and how can it be prevented? Genet in Med 2001; 5: 354-358.

8 Read A: Genetics and insurance. Genetics Law Monitor 2002; 2: 4-7.

9 McGleenan T: Legal and policy issues in genetics and insurance. Community Genet 2000; 3: 45-49.

10 Aktan-Collan K, Haukkala A, Kääriäinen H: Life and health insurance behaviour of individuals having undergone a predictive genetic testing programme for hereditary nonpolyposis colorectal cancer. Community Genet 2001; 4: 219-224.

11 MacDonald AS: Moratoria on the use of genetic tests and family history for mortage-related life insurance. Occasional Paper, 2002.

12 Subramanian K, Lemaire J, Hershey JC et al: Estimating adverse selection costs from genetic testing for breast and ovarian cancer : the case of life insurance. Journal of Risk and Insurance 1999; 66: $531-550$

13 Irish Insurance Federation: Code of practice on genetic testing, 2001. Online: http://www.iif.ie/codes.htm (date accessed: November 27 2001) art.13.

14 The Australian Investment and Financial Services Association Limited (IFSA): IFSA's policy on genetic testing, 1999 online: $<$ Web/Attach.nsf/Attachments/WG++Genetics $\sim$ Genetic+Testing+ Policy 990200_ IFSA+ Policy +on+Genetic+Testing +\%2Epdf/ $\$$ File/990200_ IFSA+Policy+on+ Genetic+Testing+.pdf > (date accessed: October 16 2001) art. 10.5.

15 Canadian Institute of Actuaries, Statement on genetic testing and insurance, 2000, November 13, 2000, Canadian Institute of Actuaries, http://www.actuaries.ca/publications/2000/20065e.pdf (date accessed: August 1, 2002 p3.

16 Murray TH: Genetic exceptionalism and 'future diaries': is genetic information different from other medical information?; in Rothstein MA (ed): Genetic Secrets: Protecting Privacy and Confidentiality in the Genetic Era. New Haven, 1997.

17 Consortium on Pharmacogenetics: Ethical and regulatory issues in research and clinical practice, 2002. online: <http:// www.bioethics.umn.edu/events > (date accessed: December 2, 2001). 